\title{
CORRIGENDUM
}

\section{Past climate changes explain the phylogeography of Vitellaria paradoxa over Africa}

F Allal, H Sanou, L Millet, A Vaillant, L Camus-Kulandaivelu, ZA Logossa, F Lefèvre and J-M Bouvet

Heredity (2011) 107, 601; doi:10.1038/hdy.2011.112

Correction to: Heredity (2011) 107, 174-186; doi:10.1038/ hdy.2011.5

Upon publication earlier this year in Volume 107, the authors noticed a typographical error, regarding the era of study, in the Discussion section. Within the paragraph sub headed 'A phylogeographic pattern driven by climate changes', a sentence on page 184 should read:
Palynological studies reported human migrations and agropastoral activities involving shea trees 1000 years ago in Burkina (Neumann et al., 1998), and the evidence of human selection of $V$. paradoxa has been found in this zone (Lovett and Haq, 2000; Maranz and Wiesman, 2003).

The authors apologize for any confusion caused. 